\title{
Margaret McCartney: Why ask, if you ignore the answer?
}

\author{
Margaret McCartney general practitioner
}

Glasgow

Creating a committee to examine the evidence, but then ignoring it, is a waste of a committee and risks wasting public money that could be better spent elsewhere.

The UK National Screening Committee (UKNSC) is the screening equivalent of NICE. As an organisation it is thorough, evidence based, and balanced in describing harms as well as benefits. It even reaches my complimentary status of "boring." It regularly reviews evidence and publishes conclusions. It does not currently recommend lung cancer screening. ${ }^{1}$

And yet: press coverage has excitedly described new lung cancer screening, which has been commissioned in some areas of mid-England. The University Hospital of South Manchester put out a press release stating, "Early diagnosis rates soar during UK-first community scanner pilot in Manchester," and the chief executive of Macmillan Cancer Support said that it showed "extraordinary success in diagnosing lung cancer at an early curative stage."

On the front page of Macmillan's booklet about the scheme a doctor says, "We have hard evidence now that CT [computed tomography] scanning high-risk patients helps us to identify cancers early enough to cure them." Alliance Medical seems to have supplied the CT scans, and the current commissioned screening is not part of a trial.

There is evidence, mainly from North America, that using CT to screen high risk people reduces all-cause mortality. The National Lung Screening Trial, published in $2011,{ }^{4}$ compared three annual CT scans with $\mathrm{x}$ ray (absolute mortality $7.02 \% \mathrm{v}$ $7.48 \%$ at a median follow-up of 6.5 years). The number needed to screen to prevent one death from lung cancer was 320 .

The reason most countries have hesitated to introduce lung cancer screening is the eye-wateringly high false positive rate. Some $27 \%$ of patients in the first and second rounds of CT screening showed a positive test, as did $16 \%$ in the third round, and the vast majority of the first group (fewer in subsequent rounds) went on to further testing. ${ }^{5}$ Some of the issues around false positive testing are being investigated as part of the NELSON trial, currently unfolding in Europe, ${ }^{5}$ and the UK Lung Screening trial.
The reason most countries have hesitated to introduce lung cancer screening is the eye-wateringly high false positive rate

The UKNSC has a long history of being ignored — take dementia screening, for example, which it has never recommended but which Jeremy Hunt forced through despite advice to the contrary. Or NHS health checks for people aged 40 to 74, which seem to have entirely subverted UKNSC's processes.

Lung cancer screening programmes will find some cancers at first pass. The question is whether the patients in question are helped more usefully then and whether the harms incurred in achieving a diagnosis - such as the risk from radiation, the process of investigation and treatment, and the psychological impact-are worth it being done earlier. A pilot study of this nature cannot tell us this, yet the headlines implied that it could. Lung cancer screening may be useful, but it will come with the risk of harm and, if rolled out, will require careful and long term assessment, audit, and revision. I'd like to see a useful intervention offered to people at high risk of lung cancer. But what should this be, when many stop smoking services in England have had their funding cut by local authorities?

1 Public Health England. UK National Screening Committee recommendation on lung cancer screening in adult cigarette smokers. Jul 2006. https://legacyscreening.phe.org.uk/ lungcancer.

2 University Hospital of South Manchester NHS Foundation Trust. Lung cancer early diagnosis rates soar during UK-first CT community scanner pilot in Manchester by UHSM. 15 Mar 2017. https://www.uhsm.nhs.uk/news/lung-cancer-early-diagnosis-rates-soar-ukfirst-ct-community-scaner-pilot-manchester-uhsm/.

3 Macmillan Cancer Support. Macmillan lung health check pilot. Aug 2016. www.macmillan. org.uk/_images/lung-health-check-manchester-report tcm9-309848.pdf.

4 Aberle DR, Adams AM, Berg CD, et al. National Lung Screening Trial Research Team. Reduced lung-cancer mortality with low-dose computed tomographic screening. N Engl J Med 2011;357:395-409. doi:10.1056/NEJMoa1102873 pmid:21714641.

5 Yousaf-Khan U, van der Aalst C, de Jong PA, et al. Final screening round of the NELSON lung cancer screening trial: the effect of a 2.5-year screening interval. Thorax 2017;357:48-56. doi:10.1136/thoraxjnl-2016-208655 pmid:27364640.

6 Khomami N. Around $40 \%$ of local authorities cutting budgets for smoking cessation services. Guardian 13 Jan 2016. https://www.theguardian.com/society/2016/jan/13/localauthorities-budgets-stop-smoking-services.

Published by the BMJ Publishing Group Limited. For permission to use (where not already granted under a licence) please go to http://group.bmj.com/group/rights-licensing/ permissions 
